\title{
Editing Eisenhower: rethinking the urban segments of the U.S. interstate highway system
}

\author{
T. Shelton \\ University of Tennessee, USA
}

\begin{abstract}
Almost since the passage of the Federal-Aid Highway Act of 1956 (commonly known as the National Interstate and Defense Highways Act) the urban segments of the Eisenhower Interstate Highway System have been controversial. Flashpoints for protests and tools for radical reshaping of the urban fabric, over the last half century the urban sections of the system have had a profound social, environmental, and structural impact on numerous American cities.

Today the greening of the American city is a linchpin of a sustainable global future. As we look for ways to retrofit U.S. cities with green infrastructures, the elimination of urban interstate segments could create intriguing sites for these developments within the otherwise crowded and difficult urban landscape. Editing Eisenhower explores this possibility.

Through an analysis of urban interstate typologies, candidate cities are identified. One city is then investigated in detail with attention given to each of the various conditions of interstate/urban interface encountered along the spine of the right-of-way. For each condition, strategies are suggested for the placement and integration of new green infrastructure. Through a series of diagrammatic studies possibilities for reshaping each condition are presented. In this way, the urban segments of the Eisenhower System are seen as having played an unexpected role in the development of the American city - that of placeholder within the urban fabric for infrastructures unimaginable at the time of their construction.
\end{abstract}

Keywords: urban, infrastructure, highways, sustainability, retrofitting. 


\section{Introduction}

The Dwight D. Eisenhower National System of Interstate and Defense Highways, most often referred to simply as the Interstate Highway System, is the largest piece of infrastructure ever created. During a half century of existence it has done what infrastructure often does - underpinned a way of life so thoroughly that the very contours of society would be drastically altered were it removed. There is little doubt that the Interstate Highway System has been a significant benefit to the country in many ways, particularly with regard to the movement of goods and the sense of personal access to the vast continent that has, in many different guises, long been part of the American identity. Yet, these blessings have been accompanied by various curses: air and noise pollution; the environmental, fiscal, and social strains of suburban sprawl; and the destruction of vital urban neighborhoods to name a few.

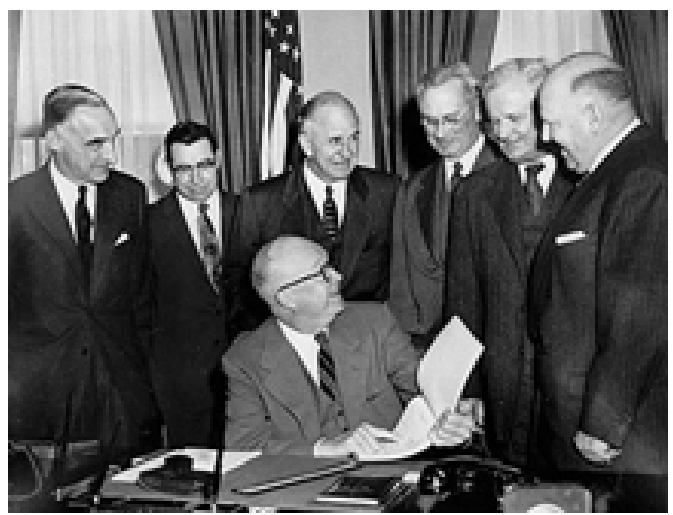

Figure 1: President Eisenhower receives the report from the advisory committee on a National Highway Program.

This paper proposes an editing of the Eisenhower System; selectively removing portions of the network where it interacts with mid-sized American cities. This reconsideration of the system promises to change its very meaning and function and profoundly alter the relationship between the city and the countryside in America. Embedded in this proposal is the notion that in these cities the Interstate Highway System has been serving a purpose never imagined for it - acting as a placeholder within the urban fabric for a host of new infrastructures that will shape the $21^{\text {st }}$ century as profoundly the interstate shaped the $20^{\text {th }}$.

\section{The interstate and the mid-sized city}

The loci of this project are the numerous places where the Interstate Highway System intersects mid sized American cities, which are here defined as cities 


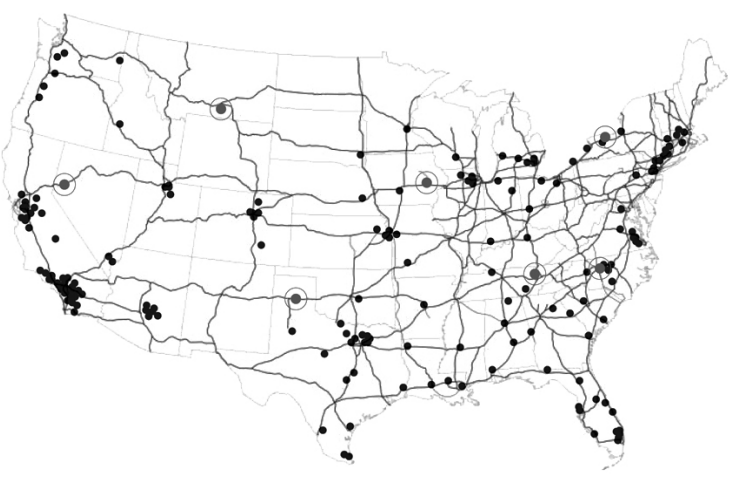

Figure 2: Relationship between U.S. mid sized cities and the Eisenhower system. Circled cities are examined in greater detail.

with populations between 100,000 and 300,000. Figure 2. This project focuses on mid sized cities for several reasons. In 2006 U.S. Census data classified 198 cities as mid sized. These cities contained a total population of 31.5 million citizens or about $11 \%$ of the total population of the country at the time. By way of comparison the 59 cities that were larger than 300,000 in 2006 contained 49.3 million people with half of those located in the ten largest cities in the country. [1]. Therefore, by using mid sized cities as the places where we edit the interstate system two goals are achieved that are vital for any infrastructure project that endeavors to be an environmental, cultural, and economic springboard for the $21^{\text {st }}$ century. First, the benefits of the project must impact the lives of a large number of people. Second, the benefits of the project must be widely dispersed geographically. The mid sized city provides a mechanism through which both of these goals are automatically achieved.

The intersection of the Interstate Highway System and the mid sized city was chosen for important structural reasons as well. In many ways this project is about undoing the damage inflicted when a particular infrastructure, the interstate highway, collided with an incompatible construct, the city [2]. It is in mid sized cities that the wounds of this collision are most apparent - in many cases the healing scars have not yet formed despite the intervention of many decades of time. It is here also that the resulting difficulties can be identified and dealt with most easily. Often in larger cities, the interstate has been subsumed by the accretion of urban growth such that the surgery necessary to allow for the healthy functioning of each has become very difficult (though still necessary in the long run.) Editing Eisenhower then is concerned with a very specific set of infrastructural conditions - mid sized cities already having bypasses as part of the Eisenhower System - that provide for the efficient restructuring of the relationship between these two entities. Figure 3.

In these locations the work of the project is very straightforward, though profound. Long-distance traffic will use the bypass to move around the city. Within the bounds of the bypass the interstate right-of-way will be recaptured as 

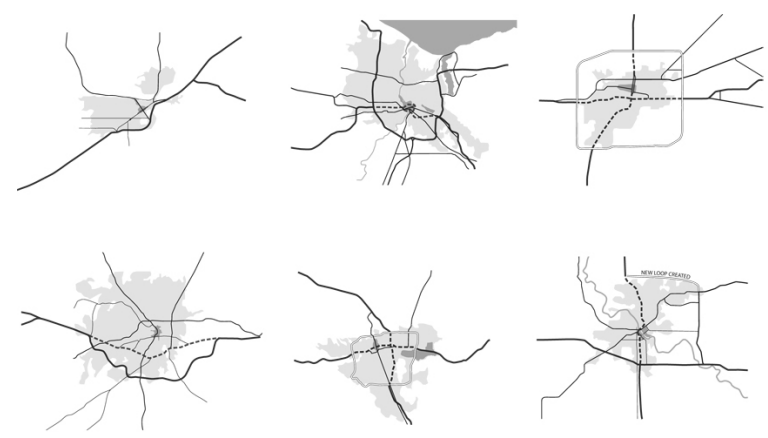

Figure 3: Interstate typologies - (clockwise from upper left) billings, MT; Rochester, NY; Amarillo, TX; Cedar Rapids, IA; Reno, NV; Greensboro, NC. Dashed lines are segments that could be removed without impacting connectivity.

an integral part of the city rather than as a portion of a sprawling continental infrastructure. This new found urban land will then be used to introduce infrastructures vital to the greening of the American city: the reconnection of historic street grids, efficient and diverse transit options, waterway and habitat protection zones, sustainable urban drainage systems, decentralized green power generation, a system of small schools, a network of public parks, urban agriculture, and significant opportunities for transit oriented infill development.

Editing Eisenhower then is an intervention that is simultaneously surgical and massive, focused and far reaching. It is, in a way, an audacious proposal, but no more audacious than the proposal for the Eisenhower System itself. That proposal has not only come to pass but has become so rooted in the fabric of our lives that taking the nearby on ramp and traveling across multiple states is so commonplace as to be completely unremarkable. It is the hope of this project that a sustainable lifestyle underpinned by the new infrastructures of Editing Eisenhower will one day be equally unremarkable for millions of Americans in mid sized cities across the country.

\section{Selective case study - Knoxville, Tennessee}

Looking at the mid sized city, Knoxville, Tennessee, as a more detailed example, the possibilities of the Editing Eisenhower project become clearer. The location of the bypass in relation to the urbanized area and central core creates a hierarchy of conditions with respect to the portions of the Eisenhower system that are to remain and those that are to be reclaimed. Primary among the goals of the proposal is the redirection of future development away from the suburban edge and toward the center city and reclaimed corridor. Figure 4. Specifically addressing each of the conditions along the corridor encourages this redirection.

Within the bypass one of the primary opportunities is the reconnecting of street grids. Figure 5. When the Eisenhower System was routed through urban 

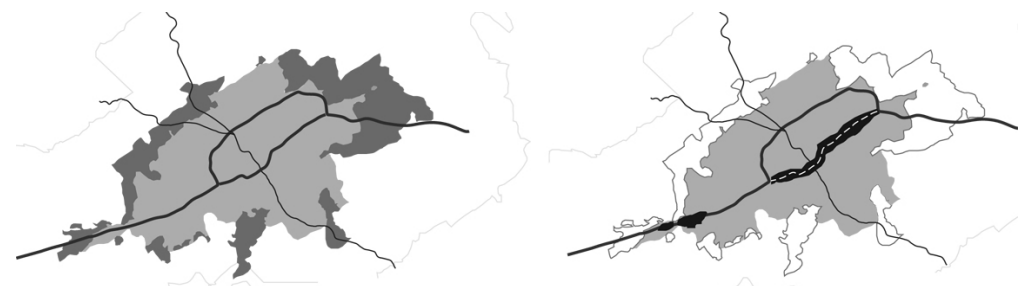

Figure 4: Knoxville, Tennessee - existing urbanized area, light gray with projected growth, dark gray (left) and refocused growth corridor (right).

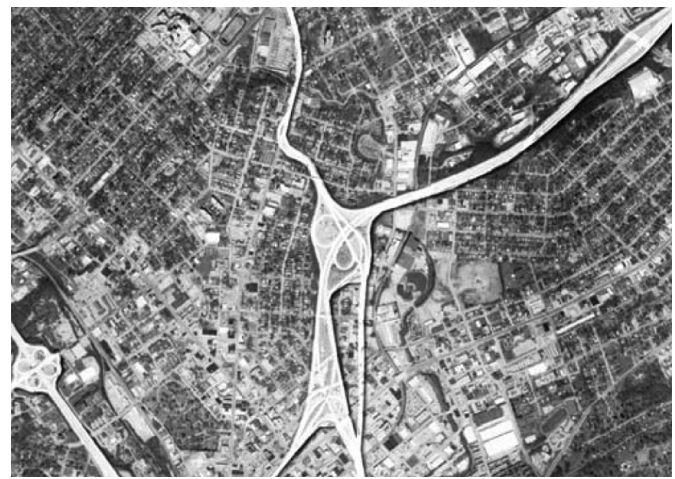

Figure 5: I-40's impact on the urban core and neighborhoods.

areas it often plowed through residential areas, disrupting the continuity of these neighborhoods and placing on them significant noise and air pollution burdens [2]. Many of these inner ring urban neighborhoods are ideal for resettlement and redesign as contemporary green neighborhoods [3].

Urban neighborhoods represent a sizeable collection of cultural artifacts and their scale, proximity to the central core, and relationship to commercial districts and transit lines make them desirable assets for the city's future. The removal of the interstate in these areas will not only allow for the introduction of selective infill and amenities, but more simply and more importantly will provide for the reconnection of the street grid, which is the lifeblood of these neighborhoods.

Away from the urban center there are two other important conditions that need to be considered in each city where interstate editing takes place. The first of these occurs at the junction of the bypass freeway and the reclaimed right-ofway (Figure 6). These locations, previously spaghetti junctions, now become important nodes of arrival into the city. It is here that one changes speeds and perhaps modes of transport. The generous size of the right-of-way at these interchanges will allow for the construction of an intermodal transportation station that will allow travelers either to transfer from private vehicles or high speed rail to trams or busses, or if remaining in their vehicle at least change to the pace of the urban boulevard from that of the interstate. 

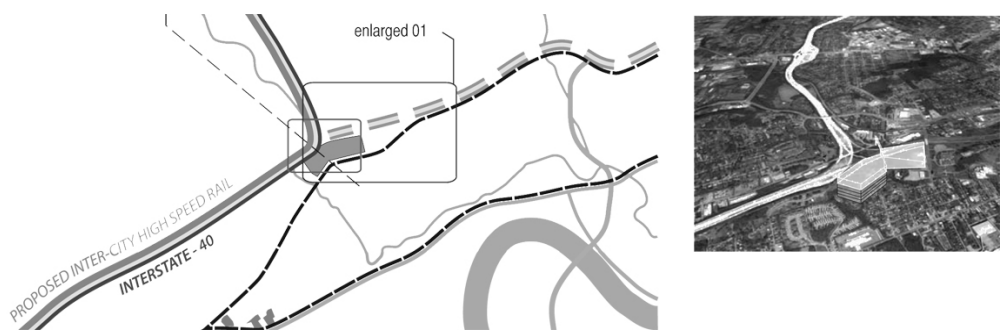

Figure 6: Junction of bypass freeway and reclaimed right-of-way.

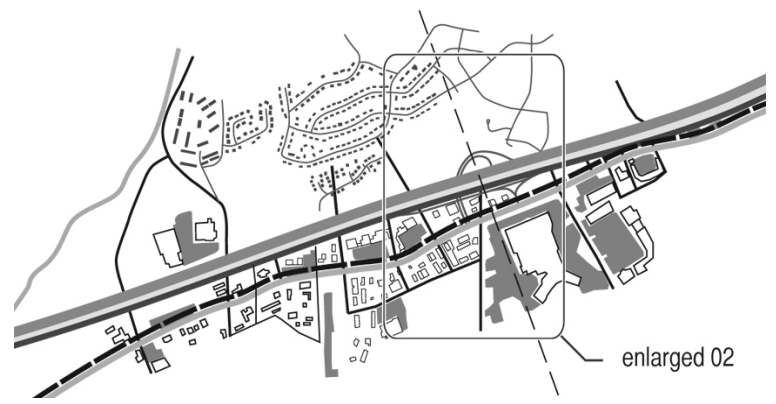

Figure 7: $\quad$ Interstate and suburban development.

The second condition occurs as one moves away from the bypass loop and into the city's suburban development (Figure 7). Here we typically find development patterns that are antithetical to the goals of Editing Eisenhower, which seeks to promote more compact, urban, energy efficient lifestyles. However, by extending some of the principles and technologies of the project to these areas some of their benefits can be realized even here and the fundamental relationship between the suburbs and the center city might be changed from one of sprawl to a network of related nodes.

\subsection{Reclaimed land}

One of the greatest benefits arising from Editing Eisenhower is the liberation of a great deal of valuable urban land. Because this land is already aligned along important corridors within the city, it is ideal for the introduction of new transit intensive avenues that provide for pedestrians, trams, and dedicated bicycle lanes in addition to automobiles (Figure 8).

Yet, this new infrastructure, along with generous planting strips only accounts for a small portion of the previous interstate right-of-way leaving a significant area available for the other new infrastructures proposed by Editing Eisenhower as well as enough infill properties to absorb the city's projected growth for many years if developed to ideal transit-oriented densities. This allows the city to greatly increase its tax base while minimizing costs associated with expanding services to the periphery. 

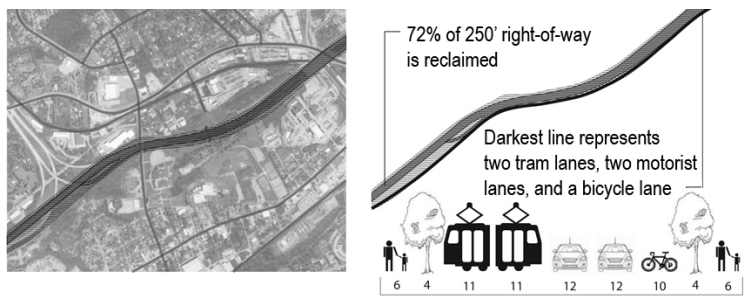

Figure 8: The I-40 right-of-way ranges from 250'- 450'. After generous space space for transit options, $72 \%$ can be converted to taxable land.

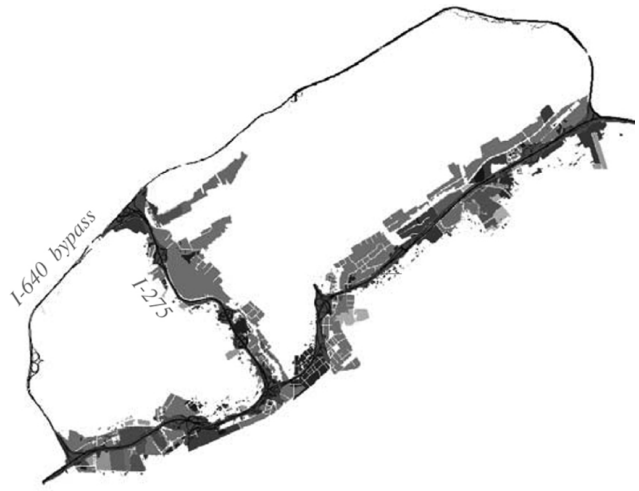

Figure 9: Public land and large scale uses adjacent to I-40 corridor.

Interstates tend to attract large scale industrial and public uses and encourage the nearby development of large parking lots (Figure 9). When these adjacent properties are taken into account, the potential impact of Editing Eisenhower is tremendous in terms of reshaping the urban landscape. Changing the nature of the relationship between the interstate and the city can serve as a catalyst for change even in suburban areas. By strategically locating stations for new intracity transit adjacent to existing interstate exits, new intermodal links are created. Encouraging cross sectional density in these areas strengthens communities and has many positive environmental effects.

\subsection{Distributed power generation}

The immense amount of contiguous land that can be freed up by Editing Eisenhower allows for the possibility of thinking in new ways about the provision of municipal utilities. Centralized utility infrastructures that exist in much of the United States, such as those for waste water treatment and power generation, will likely begin to give way to local, decentralized systems that can produce the same results through much less resource intensive means. For example, remote generation of electricity (largely used for domestic consumption) is highly inefficient with significant energy loses related to 


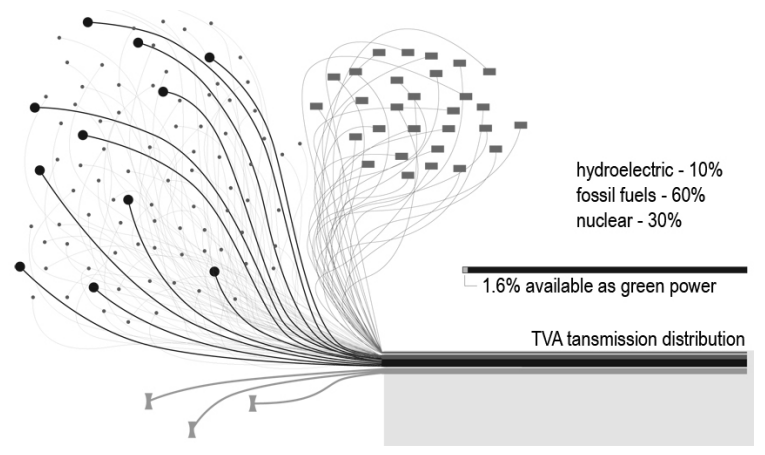

Figure 10: TVA power generation: hydroelectric $10 \%$, fossil fuels $60 \%$, nuclear $30 \%$.

generation and distribution of power. In addition, the required scale of centralized generation plants discourages the use of renewable sources of energy for electric power production. Most today rely on fossil fuels, predominantly coal [4] (Figure 10).

Whereas, small neighborhood scaled solar and wind arrays might be placed at advantageous locations along backbone of the reclaimed urban corridor to serve the adjacent neighborhoods. The large parking lots adjacent to the existing interstate are superb candidates for both wind and solar generation as they inherently have very little obstruction. Editing Eisenhower might also provide the locations for neighborhood combined heat and power (CHP) stations that, while probably running on natural gas, are extremely efficient when compared with central generation. This improved efficiency arises from a much more effective distribution tree and the capturing of "waste" heat for use in meeting local space heating needs during the winter.

\subsection{Small schools}

Public schools are considered a vital infrastructure within the Editing Eisenhower project. Not only are they an essential part of the American social contract, but access to quality schools remains a prime motivator in choice of home location. Thus, schools can be a very powerful tool in directing urban growth toward desired locations (Figure 11).

The school infrastructure proposed by the Editing Eisenhower project leans heavily on proposals made by the small schools movement. The fundamental concept of these schools is that children learn more effectively in a small environment where they know everyone and everyone else knows them. Such settings are better for discipline and are much more conducive to the faculty's ability to track children through the curriculum, addressing problems and building on strengths. In this proposal, schools districts within the interstate bypass would be broken down into smaller districts and linked with public transit, which would be free for public school children. For instance in the case 

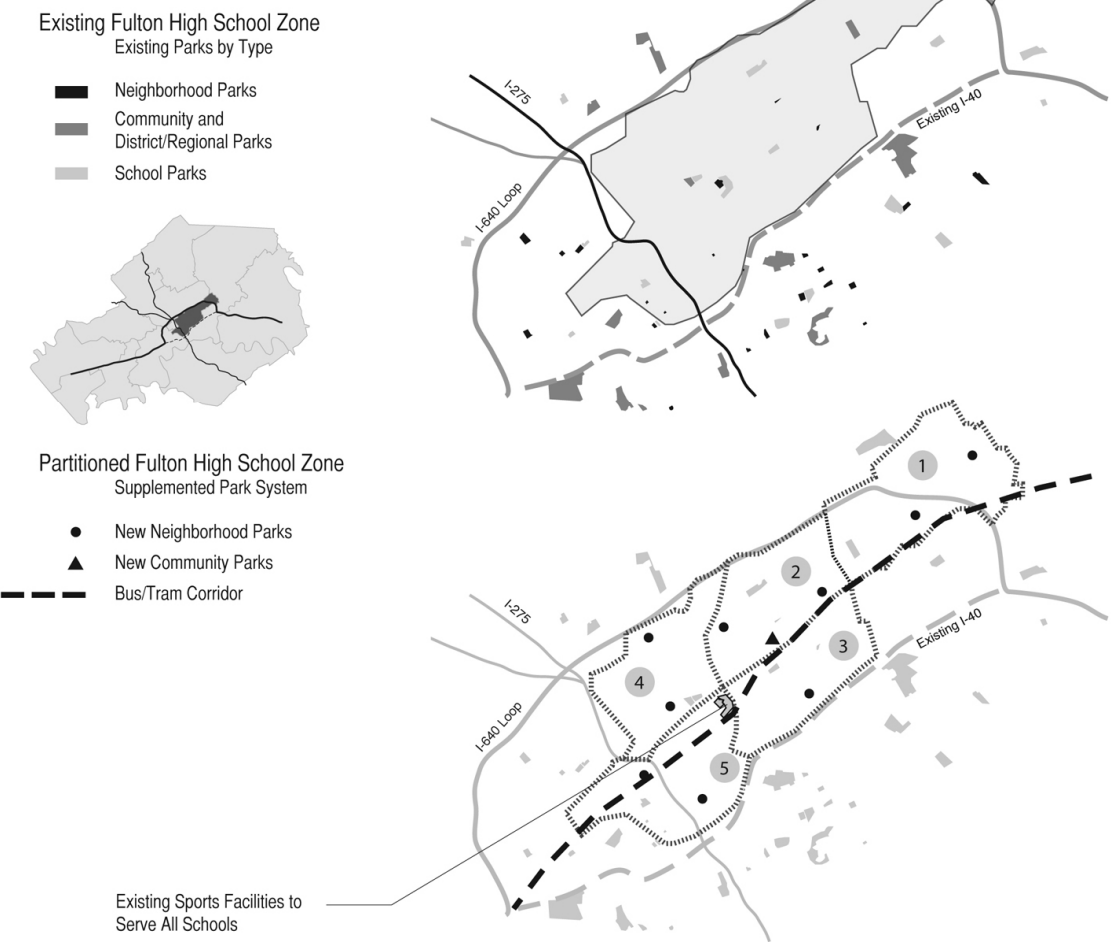

Figure 11: Small school strategy capitalizing on existing park facilities and proposed public transit.

of Knoxville, Fulton High School, which currently has about 1,000 students would initially be broken into five 200 -student academies each with a distinct specialty such performing arts or international studies. The academies would be linked for the purpose of after school programs such as clubs, band, and athletics and students would travel to these activities on free public transit.

\subsection{Sustainable urban drainage, parks, and urban agriculture}

Editing Eisenhower is an urban greening project. A key component of this is a literal greening. This project proposes to strategically intensify plant life within the urbanized area in a variety of ways. Wetlands and streams within the reclaimed district will be protected with buffers that prohibit development, allowing these fragile ecosystems the space necessary to function properly. An expansion of the city's park system will be coordinated to coincide with these protected areas wherever possible, creating larger contiguous areas for habitat and recreation. The park network is a tiered system ranging from small pocket 


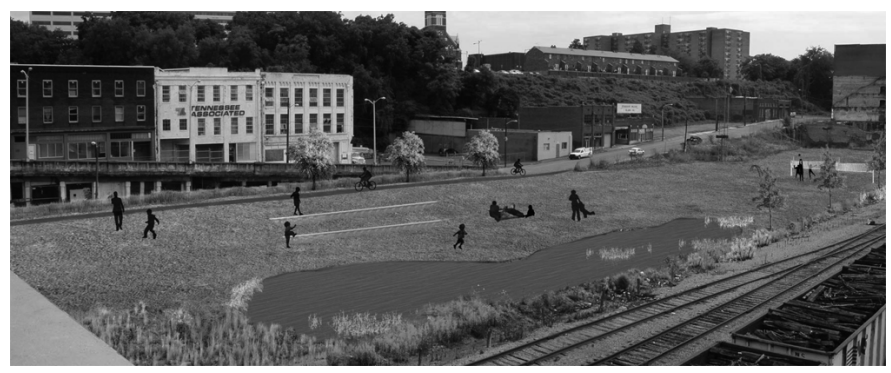

Figure 12: $\quad$ Proposed park and water retention in reclaimed right-of-way.

parks occurring frequently to large athletic fields or hiking areas being rather infrequent and serving the largest populations. Where possible, these largest types will supplement the facilities at the new public schools. Using the proposed bike lanes and land within or adjacent to the reclaimed right-of-way, all new parks will be linked by a pedestrian/bicycle greenway

Like distributed power generation systems, sustainable urban drainage systems (SUDS) are another type of distributed low-resource infrastructure. These systems, which use natural or modified topography and water tolerant plantings to impound urban runoff and allow it to seep into the ground at a more natural rate, recharging the local aquifer rather than being conveyed to a central wastewater plant and unnecessarily treated along with black water. In urban conditions these systems take a variety of forms and sizes, from sidewalk planting strips to rain gardens the size of city blocks. Editing Eisenhower proposes to begin by analyzing the floodplain for advantageous locations for large scale SUDS that will then be supplemented by a network of smaller iterations reaching out to cover the entire reclaimed site.

While it would be unrealistic to feed an entire city on the land that will be reclaimed by Editing Eisenhower, urban agriculture, both growing and composting, within the newly developed area offers a significant opportunity to close nutrient loops within the city, drastically reduce transportation energy connected with the city's food supply, and provide a source of fresh organic produce for citizens. Areas within the reclaimed area will be evaluated for solar access and adjacency to SUDS systems that might offer supplementary irrigation. The enhanced transit system will allow for these distributed growing locations to connect to a series of fresh produce markets serving neighborhoods along the corridor.

\section{Conclusion}

Viewing history from the vantage point of the present, it is tempting to think that the narratives were preordained - that the outcomes borne of actions taken long ago were as clear to some visionary planners as they are to us today. It is comforting to think that Roosevelt and his advisors were confident that the infrastructure projects of the New Deal would begin to stabilize the economy, set 
the stage for the defeat of fascism, and be useful long into the future. We want to believe that when Eisenhower gazed at a map of the proposed interstate highway system that he unquestioningly saw the expansion of American commerce and steady growth of the middle class for decades to come that would eventually win the cold war that was just beginning. We want to imbue historic men and women with the gift of foresight; with a confidence that their actions would bring about the results they desired, or at least results that would be widely positive. The story just reads better that way.

Doing so isn't fair to them or to us. It minimizes the real gravity of such decisions; makes light of the guts it takes to stand by one's vision when the stakes are so incredibly high. This tendency for writing retroactive manifestos also makes the visions themselves seem more powerful than they actually are by coating them in a patina of inevitability. Viewing history in this way underplays the validity of and sometimes completely obscures the opposing views of the day. Fortunately the struggle over the place of the interstate highway in the American city gained a vociferous and vocal advocate in the person of Jane Jacobs. She insisted that the other side of the story be heard and in doing so scored the first significant victory in a conflict that rumbles on today on battlegrounds like Seattle's Alaskan Way Viaduct, Boston's Big Dig, and Octavia Street in San Francisco.

We must remember then that the results of our actions are not foregone conclusions. We know only this. Americans are the world's great consumers, accounting for about $2 / 3$ of worldwide resource use. $80 \%$ of us live in urban areas. If we are to live up to even the most minimal of our global responsibilities in the next century we must learn to live effective, happy, low-energy, resource smart lives in cities. If we are to lead in the world during the coming century, we must do so boldly and quickly. As it is comforting for us to assign prescience to leaders of the past, it would likewise be comforting to possess it ourselves; to confidently sketch out the answer on the back of an envelope and be assured of its effectiveness. Alas, as always, such problems require of us a vision and an iron stomach. Editing Eisenhower proposes to suggest some small part of a vision by removing from cities an anti-urban infrastructure and inserting a host of urban infrastructures in its place. The hope, of course, is that infrastructure will, as mentioned in the introduction, underpin a way of life so solidly that it becomes inevitable.

\section{Acknowledgement}

The author thanks Michael Clapp for his assistance with the development of this project, particularly the creation of diagrams and renderings.

\section{References}

[1] U.S. Census Bureau at http://factfinder.census.gov

[2] See for example: Fullilove, M., Root Shock: How Tearing Up City Neighborhoods Hurts America, Random House, New York, 2004. 
386 Eco-Architecture III

[3] Shelton, T., "Visualizing Sustainability in Urban Conditions" in Eco Architecture II: Harmonisation between Architecture and Nature, ed. G. Broadbent and C.A. Brebbia, Southampton: WIT Press, 2008.

[4] http://www.tva.gov/power/ 